\title{
Punitive Damages: características do instituto nos Estados Unidos da América e transplante do modelo estrangeiro pela jurisprudência brasileira do Tribunal de Justiça de Santa Catarina
}

\author{
Punitive Damages: United States conceptualization of the doctrine and case \\ law analysis of Santa Catarina Court of Appeals
}

\author{
Rafael Peteffi da Silva \\ Universidade Federal de Santa Catarina, Florianópolis - SC, Brasil
}

Mark Pickersgill Walker

Universidade Federal do Rio Grande do Sul, Porto Alegre - RS, Brasil

\begin{abstract}
Resumo: O presente artigo busca, essencialmente, contribuir com a discussão doutrinária no que diz respeito ao instituto da indenização punitiva, conhecido, em sua origem anglo-saxônica, como punitive damages. Para esse fim, o estudo divide-se em duas partes: um primeiro momento dedica-se a esclarecer os elementos que constituem o instituto em sua origem - detalhando-se sua definição, características, funções, diferenciando-o do caráter punitivo atribuído nacionalmente às indenizações por dano moral. Já a segunda metade centra-se na análise do instituto dentro do ordenamento jurídico brasileiro - em específico com um diagnóstico detalhado de sua aplicação pelo Tribunal de Justiça de Santa Catarina.
\end{abstract}

Palavras-chave: Punitive Damages. Indenização Punitiva. Responsabilidade Civil.
Abstract: This article essentially intends to contribute with the current doctrinal discussion regarding the institute of punitive damages, as it is known in its Anglo-Saxon origins. For this purpose, the study is divided in two parts: in a brief first moment, one dedicates himself to clarify the components of the institute itself - detailing its definition and characteristics, functions, and disambiguating it from the punitive function ascribed to noneconomic damages under Brazilian law. The second half concentrates on the analysis of the institute in relation to Brazilian legal system - specifically with a detailed diagnosis of how it has been used by the Santa Catarina Court of Appeals.

Keywords: Punitive Damages. Tort Law. Comparative Law. Case-law Analysis.

Recebido em: 02/04/2016

Revisado em: 29/07/2016

Aprovado em: 09/10/2016 
Punitive Damages: características do instituto nos Estados Unidos da América e transplante do modelo estrangeiro pela jurisprudência brasileira do Tribunal de Justiça de Santa Catarina

\section{Introdução}

Os punitive damages, aqui chamados de indenização punitiva ${ }^{1}$, constituem um instituto jurídico concebido e desenvolvido historicamente no sistema jurídico da Common Law, buscando a punição de condutas especialmente gravosas dentro da esfera cível da Tort Law, análoga à nossa responsabilidade civil. O instituto despertou o interesse nacional nos anos recentes, sendo sua recepção por muitos defendida como ferramenta útil a uma apontada tendência de dinamismo nesta matéria, que buscaria uma ruptura com o apego exclusivo à tradicional função indenizatória ${ }^{2}$. Internacionalmente, o instituto também ganhou novo protagonismo diante dos movimentos de unificação da responsabilidade civil ocorridos na União Europeia (LANNI, 2015, p. 302-303).

No ordenamento nacional, a jurisprudência majoritária entende que a quantificação do dano extrapatrimonial pode levar em consideração um chamado "fator pedagógico-punitivo", isto é, poder-se-ia conferir importância para elementos como a culpa do ofensor e sua capacidade econômica no momento do arbitramento da indenização.

Embora se entenda, atualmente, que a distinção entre a indenização punitiva e o fator pedagógico-punitivo do dano moral não seja mais tão clara, como a jurisprudência pátria continua utilizando o fator pedagógico apenas como possibilidade de majoração do elemento compensatório, a diferenciação dos conceitos operacionais, mesmo que de forma tênue, mantém-se possível.

\footnotetext{
${ }^{1}$ Damages traduz-se para o português como indenização, e não como "danos", tendo em vista sua definição no Black's Law Dictionary, em tradução livre: "damages soma pleiteada ou outorgada a alguém a título de compensação por perda ou injúria" (GARNER, 2009, p. 445). Dano, por sua vez, é somente o vocábulo no singular: “damage - perda ou injúria à propriedade ou pessoa" (GARNER, 2009, p. 445). Destarte, visando até mesmo tornar mais costumeira a utilização do termo em língua portuguesa, sempre que possível intitular-se-á o instituto como "indenização punitiva", evitando também a avessa tradução como danos punitivos, conforme também destacado por Martins-Costa e Pargendler (2005), p. 16.

${ }^{2}$ A exemplo de Andrade (2009, p. 219-220); Pires (2014, 265-269), Rosenvald (2013, p. 63-69), Venturi (2014 p. 41-52). Defendendo de maneira mais geral uma função punitiva intrínseca à responsabilidade civil, Bittar (1999, p. 232-233).
} 
Com vistas a embasar uma crítica da forma como os tribunais pátrios - em especial o de Santa Catarina - vêm enfrentando a questão, o presente artigo busca inicialmente uma definição sucinta do instituto da indenização punitiva, ressaltando suas características essenciais e funções. Em seguida, são analisados pontualmente os acórdãos que fazem referência expressa ao instituto em suas ementas, julgando-se sua conformação aos princípios e ditames estabelecidos no momento anterior, para que se possa, portanto, extrair conclusões acerca da (in)adequação da jurisprudência nacional na importação da figura estrangeira. Com vistas a uma análise mais superficial, puramente quantitativa, dados de outros tribunais, como os demais tribunais da região Sul e o Superior Tribunal de Justiça, serão utilizados; a pesquisa qualitativa, contudo, ficará restrita ao Tribunal de Justiça de Santa Catarina.

Mister destacar, por fim, que não será abordado, nesse trabalho, a discussão corrente quanto a possibilidade de recepção do instituto pelo ordenamento pátrio, nem os eventuais argumentos a favor ou em contrário dessa recepção, seja ela por via jurisprudencial ou de lege ferenda. O enfoque será exclusivamente dedicado ao diagnóstico jurisprudencial. Igualmente, não se tecerá juízo de valor sobre o chamado fator punitivo do dano moral, largamente utilizado pelos tribunais brasileiros.

\section{Os Punitive Damages}

Alguma atenção à perspectiva histórica do instituto é necessária para avaliar adequadamente os casos modernos que o aplicam (SULLIVAN, 1977, p. 208). A indenização punitiva surgiu na Inglaterra, no século XVIII (Huckle v. Money, 1763; Wilkes v. Wood, 1763; BELLI, 1980, p. 4; RUSTAD; KOENIG, 1993, p. 1.287-1.288; OWEN, 1994, p. 369)',

\footnotetext{
${ }^{3}$ Com as escusas necessárias, elucida-se que por uma questão de opção de estilo, e mesmo para facilitar a leitura e a compreensão, doravante as citações diretas ou indiretas de decisões estrangeiras da Common Law, quando a íntegra ou parte dessas tiverem constituído material base do posicionamento exposto, não se darão em sua forma tradicional da ANBT - que, no caso aqui referenciado, deveria ser: "(INGLATERRA, 1763a)" - e sim em seu formato mais convencional "(Autor v. Réu, ano)". As referências ao final estarão dispostas no padrão nacional.
} 
inicialmente sendo utilizada como um instrumento jurídico visando conter abusos de poder por parte do Estado ${ }^{4}$. Sua aplicação não se restringiu a esses casos específicos: seu escopo logo se ampliou para coibir demais abusos de poder econômico ou abusos de poder em geral (RUSTAD; KOENIG, 1993, p. 1.289; OWEN, 1994, p. 369)5).

A transposição do instituto para os Estados Unidos aconteceu de maneira rápida, com uma indenização a esse título sendo reconhecida 21 anos após o primeiro precedente britânico (OWEN, 1976, p. 1.263; AUSNESS, 1986, p. 4; OWEN, 1994, p. 369) ${ }^{6}$. Foi nos Estados Unidos que a doutrina se desenvolveu para assumir os seus contornos contemporâneos mais reconhecidos e que vieram a influenciar o direito dos países de tradição romano-germânica (MORAES, 2004, p. 45-47; MARTINS-COSTA; PARGENDLER, 2005, p. 17), razão pela qual se opta por centrar a presente análise nesse país. Embora a doutrina estadunidense da indenização punitiva tenha advindo da Common Law, ela se desenvolveu independentemente de outras nações da Commonwealth, sofrendo extensivas alterações (SEBOK, 2009, p. 156).

\footnotetext{
${ }^{4}$ Os primeiros dois casos, Huckle v. Money e Wilkes v. Wood, ambos de 1763, ocorreram por consequência de um mesmo fato: a arbitrariedade estatal na emissão de mandados genéricos para a apreensão de quaisquer autores, editores e tipógrafos envolvidos na publicação do número 45 de um periódico intitulado North Briton, em razão de o panfleto possuir um teor manifestamente contrário ao governo do rei George III. Pelo menos 49 pessoas, dentre eles os dois autores das ações referidas, foram presas. No julgamento, foi conferida uma "indenização exemplar" aos dois autores em suas respectivas actions of trespass (RUSTAD; KOENIG, 1993, p.1287-1288). Foram nestes dois casos que as cortes inglesas expressaram pela primeira vez que os "propósitos punitivo e dissuasório de uma indenização podiam ser separados de sua função compensatória” (GOTANDA, 2003, p. 8).

${ }^{5}$ Gotanda (2003, p. 8) cita que passada uma década do primeiro caso britânico, as cortes comumente conferiam indenizações punitivas ou exemplares em ações de torts como assault, false imprisonment, defamation, seduction, malicious prosecution e trespass, mas nunca em casos de inadimplemento contratual.

${ }^{6} \mathrm{O}$ caso a recepcionar o instituto foi Genay v. Norris, de 1784.
} 


\subsection{Definição Elementar e Características Contemporâneas}

A indenização punitiva é definida como "[...] a indenização, não compensatória ou nominal, conferida com intuito de punir alguém por sua conduta ultrajante e dissuadir o ofensor e outros como ele de condutas similares no futuro" (Restatement (Second) of Torts $\S 908,1979)^{7}$. Um júri (ou um juiz, sob algumas circunstâncias) pode conferir a indenização punitiva em casos em que se conclua que o réu causou o dano ao autor de maneira intencional ou "maliciosa", ou ainda quando sua conduta reflita um desprezo consciente, negligente, arbitrário, ou opressivo pelos direitos ou interesses do lesado (OWEN, 1976, p. 1.265-1.266; OWEN, 1994, p. 364; SEBOK, 2009, p. 155) ${ }^{8}$. Nenhum estado permite a indenização punitiva em casos de simples ou mera negligência (MINER, 1975, p. 669; OWEN, 1976, p. 1361; SASSAMAN, 1980, p. 89; SEBOK, 2009, p. 155).

Esse tipo de indenização pode ser conferido contra um empregador por ato de seu empregado, embora alguns estados restrinjam essas indenizações a casos em que o empregador tenha ordenado, participado ou consentido com a conduta ilícita. $\mathrm{O}$ dano causado ao lesado pode ser físico, emocional, financeiro, ou envolver algum dano à propriedade.

\footnotetext{
${ }^{7}$ No original: "[...] damages, other than compensatory or nominal damages, awarded against a person to punish him for his outrageous conduct and to deter him and others like him from similar conduct in the future". Ainda, definição do Black's Law Dictionary: “[...] indenização concedida adicionalmente à indenização compensatória quando o réu agiu com negligência grave, malícia ou dolo; especificamente, uma indenização avaliada como forma de penalizar o autor do delito ou criar um exemplo aos demais, não sendo geralmente pleiteáveis em casos de inadimplemento contratual" (GARNER, 2009, p. 448). No original: "Damages awarded in addition to actual damages when the defendant acted with recklessness, malice, or deceit; specif. damages assessed by way of penalizing the wrongdoer or making an example to others. Punitive damages, which are intended to punish and thereby deter blameworthy conduct, are generally not recoverable for breach of contract".

${ }^{8}$ No original: "[...] the defendant is found to have injured the plaintiff intentionally or 'maliciously', or in which the defendant's conduct reflected a 'conscious', 'reckless', 'wilful', 'wanton', or 'oppressive' disregard of the rights or interests of the plaintiff'. Owen (1988, p. 730) acrescenta que essa conduta deve também constituir um desvio extremo de uma conduta lícita.
} 
O montante indenizatório é determinado pelo júri através de consideração sobre a seriedade do ilícito, a gravidade do dano sofrido pelo lesado, e a capacidade financeira do lesante (OWEN, 1976, p. 1.266-1.267; OWEN, 1994, p. 364-365; SEBOK, 2009, p. 155)9.

A indenização punitiva em regra só pode ser conferida após se determinar que o réu é responsável pelo dano causado ao autor e, em boa parte dos estados, também só após a consideração do valor apropriado a título compensatório por esse dano (SEBOK, 2009, p. 171). Em alguns estados, tal procedimento ocorre de maneira "bifurcada", com o júri tratando dos diferentes elementos da indenização (a parte compensatória e a parte extracompensatória) e suas respectivas quantificações em etapas diferentes do julgamento ${ }^{10}$.

Compensatory damages ("indenização compensatória"; também chamada de actual damages, tangible damages, ou real damages), para contribuir com uma definição por contraste, como seu próprio nome alude, é uma indenização que se submete ao princípio da reparação integral; ou seja, uma indenização em quantia suficiente para indenizar o lesado pelo dano comprovadamente sofrido (GARNER, 2009, p. 445). Destarte, a indenização compensatória guarda uma relação lógica, em seu caráter jurídico, com a ótica reparatória da responsabilidade civil brasileira ${ }^{11}$.

Na correlação entre as duas figuras - os punitive damages e os compensatory damages - afirma Keeton (1984, p. 14-15):

[...] é frequentemente afirmado também que a indenização punitiva deve guardar alguma proporção, ou pelo menos algum tipo inde-

\footnotetext{
${ }^{9}$ Sobre a capacidade financeira do lesante ainda Keeton (1984, p. 15): “[...] a maioria das cortes concorda que evidências sobre as condições financeiras do réu podem ser utilizadas por ajudarem a sanar a questão de quê montante adequadamente puniria o réu por sua conduta”. No original: “(m)ost courts agree that evidence of the defendant's wealth may be received as bearing on the question of the amount which will adequately punish the defendant for the conduct".

${ }^{10}$ Dentre eles, Califórnia, Montana, Nevada, New Jersey, Texas e West Virginia (KOZIOL; WILCOX, 2009, 311-321).

${ }^{11}$ Essa é também a lógica primordial da tort law (Keeton, 1984, p. 9; SAles, Cole JR. 1984, p. 1.118).
} 
finido de relação, à indenização compensatória determinada, para garantir que uma indenização compensatória muito pequena não receba uma penalidade muito grande. ${ }^{12}$

\subsection{Funções da Indenização Punitiva no Ordenamento Jurídico Esta- dunidense}

No que diz respeito às funções do instituto em questão, o seu propósito principal, na origem da maioria das jurisdições que o utilizam, sempre foi identificado com o intuito de punir o ofensor da conduta e dissuadir ou desestimular este ofensor e terceiros de agir desta mesma forma. O Restatement (Second) of Torts corrobora essa compreensão (LONG, 1976, p. 876; BELLI, 1980, p. 6; OWEN, 1994, p. 364). As teorias da punição e dissuasão - chamadas nos países da common law de punishment $\mathrm{e}$ deterrence - são trabalhadas por Keeton $(1984$, p. 9):

A ideia de punição, ou de desencorajar outras ofensas, usualmente não entra na responsabilidade civil, exceto na medida em que possa levar os tribunais a balancear as coisas em favor dos interesses dos autores em determinar se um ilícito foi efetivamente cometido. Em casos onde $\mathrm{o}$ ato do réu foi intencional e deliberado, e teve o caráter de indignação frequentemente associado aos crimes, quase todos os tribunais vêm permitido ao júri conceder numa ação de responsabilidade civil uma indenização a título "punitivo" ou "exemplar", ou por vezes chamada "smart money". Tais danos são concedidos em adição e em separado da compensação integral pelo dano sofrido, com o propósito de punir o agente, de ensiná-lo a não cometer o ilícito novamente, e dissuadir terceiros de seguir seu exemplo ${ }^{13}$.

\footnotetext{
${ }^{12}$ No original: "[...] (i)t frequently is said also that punitive damages must bear some reasonable proportion, or at least some undefined kind of relation, to the actual damages found, so that a very small award of compensation will not support a very large penalty". ${ }^{13}$ No original: "The idea of punishment, or of discouraging other offenses, usually does not enter into tort law, except in so far as it may lead the courts to weight the scales somewhat in favor of the plaintiff's interests in determining that a tort has been committed in the first place. In one rather anomalous respect, however, the ideas underlying criminal law have invaded the field of torts. Where the defendant's wrongdoing has been intentional and deliberate, and has the character of outrage frequently associated with
} 
Em brevíssimo retrospecto histórico, cumpre destacar que o aspecto punitivo foi estabelecido em decisão judicial da Suprema Corte dos Estados Unidos do ano de 1851 - Day v. Woodworth. Já o aspecto de dissuasão da teoria pode ser claramente apreendido de decisão de 1850 da Suprema Corte do Tennessee - Polk, Wilson \& Co. v. Fancher (LONG, 1976, p. 876-877).

A função eminentemente punitiva também é intitulada de desert e tem sua lógica fulcrada no fato que a conduta do causador do dano é tida como errada num sentido moral, fazendo com que o ofensor mereça sofrer por seu ilícito, independentemente se isso vai lhe reformar o caráter ou dissuadir suas condutas futuras ou servir de exemplo aos demais. É um objetivo por vezes chamado também de retributivo (DOBBS, 1989, p. 844). Owen aponta que essa forma de retribuição é apropriada, pois as condutas passíveis de punição são de natureza quasi-criminal ("quase criminal”) (OWEN, 1994, p. 375).

Em relação à segunda função essencial, Owen (1994, p. 377) aponta que a eficácia da dissuasão depende de dois fatores centrais: (a) se o ordenamento jurídico, por meio da indenização punitiva, de fato pune as pessoas que violem flagrantemente os direitos de outrem e (b) se potenciais ofensores compreendem o que o instituto prescreve, sabendo que serão passíveis de punição.

Dobbs sistematiza o conceito de dissuasão dividindo-o entre a dissuasão stricto sensu ou specific deterrence ("dissuasão específica") e a exemplaridade ou general deterrence ("dissuasão geral”). O primeiro diz respeito à dissuasão que age sobre o próprio ofensor, ao sofrer a punição que lhe é conferida por sua conduta, e o segundo, à dissuasão que age sobre terceiros ao notarem o exemplo da punição sofrida pelo ofensor -

crime, all but a few courts have permitted the jury to award in the tort action 'punitive' or 'exemplary' damages, or what is sometimes called 'smart money'. Such damages are given to the plaintiff over and above the full compensation for the injuries, for the purpose of punishing the defendant, of teaching the defendant not to do it again, and of deterring others from following the defendant's example". 
surgindo daí o outro nome pelo qual o instituto é comumente intitulado, “indenização exemplar” (DOBBS, 1989, p. 844-846) ${ }^{14}$.

Além das funções vistas como essenciais, os teóricos da questão costumam apontar uma gama de outras funções que o instituto cumpre, em geral deduzidas a partir dos próprios argumentos dos julgadores em casos em que a indenização punitiva foi deferida.

A dissuasão geral como sistematizada por Dobbs, por exemplo, é por vezes elaborada e concebida até mesmo em momento anterior a uma indenização específica, em uma função própria intitulada education ("educação"). A função educativa se cumpre ao divulgar para o público geral a existência de um direito juridicamente protegido e as consequências que resultam de uma grave quebra das regras da sociedade. Também se cumpre essa função educativa ao tornar pública a informação sobre potenciais perigos como maus médicos ou produtos defeituosos (OWEN, 1994, p. 374-375; CADY, 1997, p. 1.010).

Um objetivo secundário de grande destaque, e que normalmente causa grande consternação no jurista brasileiro, é o da compensation ("compensação"). Surge a partir do fato que muitos elementos tidos como danosos não são passíveis de indenização e, portanto, poderiam ser abarcados pela indenização punitiva (BELLI, 1980, p. 6; OWEN, 1994, p. 378-379). O grau de proeminência desta função varia de Estado para Estado: alguns, como Connecticut, controversamente tratam a função compensatória como a exclusiva ou pelo menos a mais importante da indenização punitiva, enquanto o Texas só concebe sua utilidade em situações de compensação dificultada no sistema jurídico da Common Law, como sofrimentos emocionais e psíquicos, danos puramente econômicos ${ }^{15}$ e demais danos similares (LONG, 1976, p. 875-876).

Keeton também já contemplara essa função afirmando que "[...] decisões ocasionalmente mencionam o propósito adicional de reembolsar o

\footnotetext{
${ }^{14}$ É o nome que se prefere dar ao instituto na Inglaterra (KOZIOL; WILCOX, 2009, p. 1). 15 Para uma noção inicial da categoria de "danos puramente patrimoniais", raramente tratada pelos doutrinadores brasileiros, veja-se Silva e Rodrigues Junior (2015).
} 
autor por elementos do dano que não são geralmente compensáveis, como dissabores emocionais ou as despesas do litígio" (KEETON, 1984, p. 9) ${ }^{16}$.

A última função apontada da indenização punitiva é chamada policing ou law enforcement ("policiamento") e visa encorajar que indivíduos e seus advogados proponham ações contra ofensores nas situações em que sua conduta tenha sido de natureza ultrajante - incentivando que entes privados ajam em prol do interesse público (AUSNESS, 1986, p. 69; OWEN, 1994, p. 380-381; KAUFMAN, 2003, p. 5).

Essa função se vê pautada exclusivamente no incentivo financeiro que é oferecido ao lesado ${ }^{17}$. Ela serve como um argumento para que o autor da ação mereça ser recompensado, mas não como um argumento do para que os réus devam sofrer um prejuízo. Assim sendo, é uma função claramente auxiliar que não se sustenta individualmente (ELLIS JR., 1982, p. 10).

\subsection{Desambiguação Realizada pela Doutrina Brasileira entre a Indeni- zação Punitiva e o Caráter Punitivo-Pedagógico do Dano Moral}

Sanseverino alerta que a ênfase que vem sendo conferida à função punitiva do dano moral deveria ser feita com cautela, para não ensejar confusões com a indenização punitiva da common law (SANSEVERINO, 2010, p. 273). Para o autor, a primeira estaria abarcada por sua construção teórica da integralidade das reparações, sendo parte componente das reparações por dano moral (SANSEVERINO, 2010, p. 272 e 275), enquanto a segunda seria incompatível com nossa tradição jurídica, e carente de respaldo legal (SANSEVERINO, 2010, p. 273).

Concorda o autor também com nosso diagnóstico jurisprudencial, infra, asseverando que "[...] (a)s referências feitas pelos tribunais, no arbitramento de indenizações por danos extrapatrimoniais, à sua natureza pu-

\footnotetext{
16 Importante esclarecer que no sistema jurídico estadunidense, independentemente de ter ganhado ou não a causa, afirma-se que cada parte deve arcar com suas próprias custas e honorários advocatícios - tal regra é chamada the American rule (EISENBERG; MILLER, 2013, p. 328-329).

${ }^{17}$ Calabresi (1970) chamava, de forma não pejorativa, incentivos desse tipo de "subornos" previsto pela legislação.
} 
nitiva não enseja, por si só, que elas se enquadrem como modalidades de punitive damages" (SANSEVERINO, 2010, p. 75-76). Em sua opinião, nesses casos se teria um arbitramento equitativo da indenização por danos extrapatrimoniais (SANSEVERINO, 2010, p. 273).

Em seu artigo especificamente sobre o tema, também Judith Martins-Costa e Mariana Pargendler evidenciam como a construção dos dois institutos se deu através de processos históricos distintos, mesmo que possivelmente advindos de uma mesma origem: a pena privada aplicada aos delicta na tradição romanística clássica (MARTINS-COSTA; PARGENDLER, 2005).

Fernando Noronha não discorre em sua obra especificamente sobre o instituto da indenização punitiva, mas admite uma função sancionatória e preventiva para a responsabilidade civil, alertando quanto a esta segunda que não se deve exagerar na ideia do valor de desestímulo associada à ideia dos punitive ou exemplary damages da jurisprudência norte-americana, sendo possível extrair que o autor lhe reconhece influência sobre o nosso sistema, sem confundir a indenização punitiva com a função sancionatória e preventiva da responsabilidade civil (NORONHA, 2013, p. 461-464).

Moraes identifica que o julgamento moral das condutas que geraram danos (cuja compensação constituiria "o dinheiro da dor") é a possível causa da expansão da tese punitiva em nosso ordenamento. Seria a partir disso que se passou a admitir a aplicação da pena privada a certas categorias de danos extrapatrimoniais. Destaca ainda o uso reiterado pela doutrina brasileira de um excerto bastante antigo sobre o tema: “[...] o pagamento de uma soma a título de satisfação ocupa um lugar intermédio entre a indenização e a pena" (MORAES, 2004, p. 52) ${ }^{18}$.

A autora se posiciona contrariamente não só à recepção da indenização punitiva como também à existência até mesmo da função punitiva da indenização extrapatrimonial (MORAES, 2004). Identifica outros autores com posição semelhante: José de Aguiar Dias, Pontes de Miranda,

${ }^{18}$ O trecho citado pela autora é de tradução de 1938 da obra $A$ reparação dos danos no Direito Civil, de H. A. Fischer. 
Wilson Melo da Silva, Orlando Gomes. Já os favoráveis a algum tipo de função punitiva seriam, em maior ou menor grau: Caio Mário da Silva Pereira, Silvio Rodrigues, Maria Helena Diniz, Artur Oscar de Oliveira Déda, Carlos Alberto Bittar, Sérgio Cavalieri, dentre outros (MORAES, 2004, p. 47).

Além dos citados por Moraes, Judith Martins-Costa e Mariana Pargendler identificam também Sérgio Severo, Humberto Theodoro Jr. e a própria Maria Celina Bodin de Moraes como autores que propugnam que, em regra, a função da reparação do dano moral é somente ressarcitória. Como favoráveis a algum tipo de função punitiva, acrescentam: Galeno Lacerda, João Casillo, Teresa Ancona Lopes, Guilherme Calmon Nogueira da Gama, Fernando Noronha e Yussef Said Cahali. Destacam ainda as autoras que a teoria mista (corrente que defende que a função da indenização do dano moral é tanto a satisfação do ofendido quanto a punição do ofensor) pode ser considerada majoritária na doutrina e jurisprudência brasileira (MARTINS-COSTA; PARGENDLER, 2005, p. 30).

Ao acolher a função punitiva da indenização por danos morais, a jurisprudência (em especial o STJ) costuma utilizar três critérios para se chegar a um valor indenizatório: (1) o grau de culpa do ofensor; (2) a condição econômica do responsável pela lesão; e (3) o enriquecimento obtido com o fato ilícito (MARTINS-COSTA; PARGENDLER, 2005, p. 23).

Conquanto similar aos critérios utilizados na determinação do montante indenizatório de uma indenização punitiva ${ }^{19}$, há uma diferença essencial: a doutrina estadunidense traz como imprescindível, até para que se cumpra corretamente os fins desse tipo de indenização, "[...] a comprovação de elementos subjetivos (culpa grave, dolo, malícia, fraude etc.) a marcarem a conduta do ofensor" (MARTINS-COSTA; PARGENDLER, 2005 , p. 23$)^{20}$.

Elucidam, in verbis, as autoras (2005, p. 22-23):

\footnotetext{
${ }^{19} \mathrm{Cf}$. explicitado nota de rodapé 9.

${ }^{20}$ Em igual sentido, Moraes (2004, p. 56-57): “[...] a indenização por punitive damages não ocorre em casos de simples culpa; ela só surge se o ofensor tiver agido com culpa grave ou dolo". Os elementos subjetivos que constituem o padrão da conduta ilícita foram também analisados nota de rodapé 8 .
} 
É preciso, pois, distinguir: uma coisa é arbitrar-se indenização pelo dano moral que, fundada em critérios de ponderação axiológica, tenha caráter compensatório à vítima, levando-se em consideração - para a fixação do montante - a concreta posição da vítima, a espécie de prejuízo causado e, inclusive, a conveniência de dissuadir o ofensor, em certos casos, podendo mesmo ser uma indenização "alta" (desde que guarde proporcionalidade axiologicamente estimada ao dano causado); outra coisa é adotar-se a doutrina dos $p u$ nitive damages que, passando ao largo da noção de compensação, significa efetivamente - e exclusivamente - a imposição de uma pena, com base na conduta altamente reprovável (dolosa ou gravemente culposa) do ofensor, como é próprio do direito punitivo.

No primeiro caso, o universo é amplíssimo, abarcando os regimes de responsabilidade resultantes de quaisquer dos critérios de imputação (subjetiva ou objetiva, seja esta pelo risco, pela segurança, pela confiança, etc.). No segundo caso, (punitive damages) só poderá abranger a responsabilidade derivada da imputação subjetiva, sob pena de incontornável contradição: se o que é avaliado (para fixar o montante da indenização) é a maior ou menor gravidade da conduta do autor do dano e o maior ou menor grau de reprovação ético-jurídica à conduta, como fazê-la incidir às hipóteses de imputação objetiva, para a qual o exame da conduta do agente é despiciendo (examinando-se tão-só a ilicitude, o dano, a imputabilidade e o nexo causal)?

Conforme já exposto, no ordenamento estadunidense a indenização punitiva não está restrita às hipóteses de danos extrapatrimoniais. Um de seus desenvolvimentos recentes naquele ordenamento foi justamente sua aceitação em "business torts"21 (SEBOK, 2009, p. 165).

${ }^{21}$ Compreendidas como "[...] ilícitos que interfiram com algum aspecto de determinado interesse econômico ou com alguma relação negocial, causando um prejuízo econômico ao invés de um dano à propriedade ou à integridade física. Incluem interferências ilícitas em relações contratuais, interferências intencionais em perspectivas de vantagens econômicas, práticas negociais injustas, apropriações indevidas de segredos comerciais, e violações à propriedade industrial" (GARNER, 2009, p. 1626). No original: "A tort that impairs some aspect of an economic interest or business relationship and causes economic loss rather than property damage or bodily harm. Business torts include tortious interference with contractual relations, intentional interference with prospective 
Atualmente, entende-se que a distinção entre o instituto dos punitive damages e o fator pedagógico-punitivo do dano moral não é mais tão clara. Nos Estados Unidos, embora haja uma histórica resistência por parte da Suprema Corte em determinar uma correlação entre o montante arbitrado a título de indenização punitiva e os valores concedidos a título de indenização compensatória, encontram-se inúmeras decisões de Supremas Cortes Estaduais utilizando a indenização compensatória como uma variável limitadora importante na quantificação da indenização punitiva ${ }^{22}$.

Entretanto, como a jurisprudência brasileira, de forma majoritária, continua utilizando o fator pedagógico apenas como uma possibilidade de modulação ou majoração do elemento compensatório, sendo este ainda a baliza fundamental para a quantificação do dano moral, garantindo relati-

economic advantage, unfair business practices, misappropriation of trade secrets, and product disparagement".

22 A exemplo da Corte de Apelações da West Viriginia que, seguindo os princípios estabelecidos pelo leading case da Suprema Corte Pacific Mutual Life Insurance Co. v. Haslip, determinou: "as a matter of fundamental fairness, the punitive damages should bear a reasonable relationship to compensatory damages" (RUSTAD; KOENIG, 1993, p. 1.271). Similarmente, a Suprema Corte já havia pronunciado duas vezes que indenizações punitivas com montantes superiores a nove vezes o valor da indenização compensatória teriam alta probabilidade de serem inconstitucionais, por ferirem o processo legal ( $B M W$ v. Gore, 1996; State Farm v. Campbell, 2003). Ainda, Sebok (2007, p. 959) ressalta que, ao contrário do que propagam os tort reformers, a indenização punitiva não está, nem nunca esteve, perto de sair do controle. Em igual sentido, trazendo evidências empíricas que desconstroem a caracterização alegórica dos punitive damages enquanto indenizações milionárias que não guardam qualquer correlação com os fatos concretos: Daniels e Martin (1990); Rustad e Koenig (1993, p. 1.330-1.333); Owen (1994, p. 371-373). Em relatório recente sobre a experiência estadunidense, conclui também Anthony J. Sebok que - para a estranheza de um jurista de tradição romano-germânica (cf. YÁGUÊZ, 2012, p. 36) a indenização punitiva é concedida raramente e de maneira previsível, tipicamente em um montante modesto se comparado com a indenização compensatória que se baseia (SEBOK, 2009, p. 156). Já no que diz respeito à suscitada incompatibilidade entre a responsabilidade objetiva e a indenização punitiva, os autores estrangeiros apontam que ela não se sustenta, uma vez que não é porque se prescinde da análise da culpa nessas hipóteses que tal análise seja vedada. Assim, no ordenamento estadunidense, mesmo nos casos em que a indenização compensatória é acobertada pela responsabilidade objetiva, se o lesado conseguir comprovar o requisito subjetivo necessário (a culpa especialmente grave do lesante), não há óbice para a concessão de uma indenização punitiva (OWEN, 1976, p. 1.269-1.271). 
va conexão com o princípio da reparação integral do prejuízo, entende-se que a diferenciação dos conceitos operacionais, mesmo que de forma tênue, mantém-se possível. Destarte, em algumas poucas célebres decisões, a jurisprudência estrangeira confere indenizações vultosas a título de $p u$ nitive damages, completamente desconectadas da indenização compensatória $^{23}$.

Como se deixou claro na introdução, o presente trabalho não se presta para analisar a compatibilidade do ordenamento jurídico nacional com o instituto dos punitive damages ou com o fator pedagógico utilizado na quantificação do dano moral. O diagnóstico jurisprudencial tem como escopo exclusivo a verificação de possíveis confusões conceituais, tendo-se como base a diferenciação entre os institutos citados, realizada pela doutrina brasileira majoritária.

\section{Diagnóstico Jurisprudencial}

Feita exposição acerca das características ontológicas e funcionais do instituto enquanto concebido em suas origens na Common Law, além de diferenciá-lo do caráter punitivo-pedagógico do dano moral, passa-se ao cerne deste artigo: uma análise da aplicação do instituto pela jurisprudência do Tribunal de Justiça do Estado de Santa Catarina.

Para fins estatísticos, em primeiro lugar, fez-se um levantamento envolvendo todos os três tribunais da região Sul, o Tribunal de Justiça de São Paulo, e o Superior Tribunal de Justiça. O método exclusivo para obtenção dos resultados foi a utilização das consultas jurisprudenciais dos websites institucionais específicos de cada Tribunal analisado, com data de julgamento ${ }^{24}$ até 31 de dezembro de 2014.

\footnotetext{
${ }^{23}$ A exemplo do caso Philip Morris USA v. Williams, em que a Suprema Corte - a despeito de precedentes anteriores - permitiu que se mantivesse uma indenização punitiva em montante equivalente a 98 vezes a indenização compensatória concedida (Philip Morris USA v. Williams, 2007).

${ }^{24}$ Os recortes temporais realizados foram padronizados pelas datas de julgamento das decisões por decorrência de um impedimento material: dos tribunais analisados, o TJ-SC não disponibiliza a possibilidade de consulta por datas de publicação.
} 
Inicialmente, o levantamento se produz pela consulta através do emprego de três expressões específicas: "punitive damages" 25 , "indenização punitiva" e "danos punitivos", em acórdãos dos respectivos tribunais (excetuando-se, portanto, decisões monocráticas, acórdãos ou decisões de turmas recursais e despachos de vice-presidência, etc.). Serão apresentandos então dois totais: um para tal consulta somente nas ementas desses acórdãos e outro em relação ao inteiro teor.

O tabelamento de tais valores nos tribunais que se determinou a análise é o que segue:

Tabela 1: Consulta jurisprudencial por tribunal

\begin{tabular}{|c|c|c|c|c|c|c|}
\hline & & STJ & TJ-PR & TJ-RS & TJ-SC & TJ-SP \\
\hline \multirow{2}{*}{ Punitive damages } & Ementa & $\mathbf{5}$ & $\mathbf{2 1}$ & $\mathbf{1 5}$ & $\mathbf{1 4}$ & $\mathbf{9 8}$ \\
\cline { 2 - 7 } & Inteiro teor & $\mathbf{8}$ & $\mathbf{4 3 9}$ & $\mathbf{4 7 6}$ & $\mathbf{2 0 4}$ & $\mathbf{1 6 4 6}$ \\
\hline \multirow{2}{*}{ Indenização punitiva } & Ementa & $\mathbf{0}$ & $\mathbf{2}$ & 7 & $\mathbf{0}$ & $\mathbf{6}$ \\
\cline { 2 - 7 } & Inteiro teor & $\mathbf{0}$ & $\mathbf{1 2 8}$ & $\mathbf{2 7 2}$ & $\mathbf{9}$ & $\mathbf{1 4 2}$ \\
\hline \multirow{2}{*}{ Danos punitivos } & Ementa & $\mathbf{0}$ & $\mathbf{2}$ & $\mathbf{0}$ & $\mathbf{0}$ & $\mathbf{2}$ \\
\cline { 2 - 7 } & Inteiro teor & $\mathbf{1}$ & $\mathbf{5 5}$ & $\mathbf{1 4}$ & $\mathbf{1 7}$ & $\mathbf{8 6}$ \\
\hline
\end{tabular}

Fonte: Superior Tribunal de Justiça; Tribunal de Justiça do Rio Grande do Sul; Tribunal de Justiça do Paraná; Tribunal de Justiça de Santa Catarina; Tribunal de Justiça de São Paulo

Sem sombra de dúvida, a expressão mais utilizada ainda é em língua estrangeira, a exceção do tribunal do Rio Grande do Sul, que já traz um número de ocorrências aproximado entre a expressão estrangeira e a denominação nacional do instituto.

É possível consultar nos tribunais regionais citados as ocorrências da pesquisa pela expressão "punitive damages", em acórdãos e decisões monocráticas, separadas pelo intervalo de um ano em cada um deles, nos últimos 15 anos, com fins de se poder tirar possíveis conclusões se há uma tendência crescente ou não de referências ao instituto. Os resultados:

\footnotetext{
${ }^{25} \mathrm{Na}$ busca de dados que melhor reflitam a realidade, somaram-se a esses resultados duas ocorrências convencionais de grafias incorretas do nome do instituto: "punitive-damages" (cuja busca retorna resultados diferentes somente no TJ-SC) e "punitive damage" (cuja busca só não retorna resultados diferentes no TJ-SP).
} 
Tabela 2: Ocorrências do termo "punitive damages" na consulta ao inteiro teor de acórdãos e decisões monocráticas dos tribunais regionais em análise de 2000 a 2014

\begin{tabular}{|c|c|c|c|c|c|c|c|c|}
\hline & 2000 & 2001 & 2002 & 2003 & 2004 & 2005 & 2006 & 2007 \\
\hline TJ-SC & 9 & 1 & 9 & 9 & 8 & 12 & 2 & 1 \\
\hline TJ-RS & 0 & 0 & 0 & 5 & 1 & 10 & 12 & 3 \\
\hline TJ-PR & 0 & 0 & 3 & 1 & 11 & 7 & 17 & 35 \\
\hline TJ-SP & 6 & 6 & 1 & 8 & 8 & 15 & 62 & 54 \\
\hline & & & & & & & & \\
\hline
\end{tabular}

\begin{tabular}{|c|c|c|c|c|c|c|c|}
\hline & 2008 & 2009 & 2010 & 2011 & 2012 & 2013 & 2014 \\
\hline TJ-SC & 9 & 29 & 23 & 14 & 27 & 15 & 26 \\
\hline TJ-RS & 7 & 9 & 8 & 134 & 139 & 85 & 79 \\
\hline TJ-PR & 23 & 43 & 51 & 79 & 108 & 24 & 83 \\
\hline TJ-SP & 46 & 110 & 174 & 231 & 345 & 353 & 239 \\
\hline
\end{tabular}

Fonte: Tribunal de Justiça do Rio Grande do Sul; Tribunal de Justiça do Paraná; Tribunal de Justiça de Santa Catarina; Tribunal de Justiça de São Paulo

Ou, ainda, de forma gráfica:

Gráfico 1: Ocorrências do termo "punitive damages" na consulta ao inteiro teor de acórdãos e decisões monocráticas dos tribunais regionais em análise de 2000 a 2014

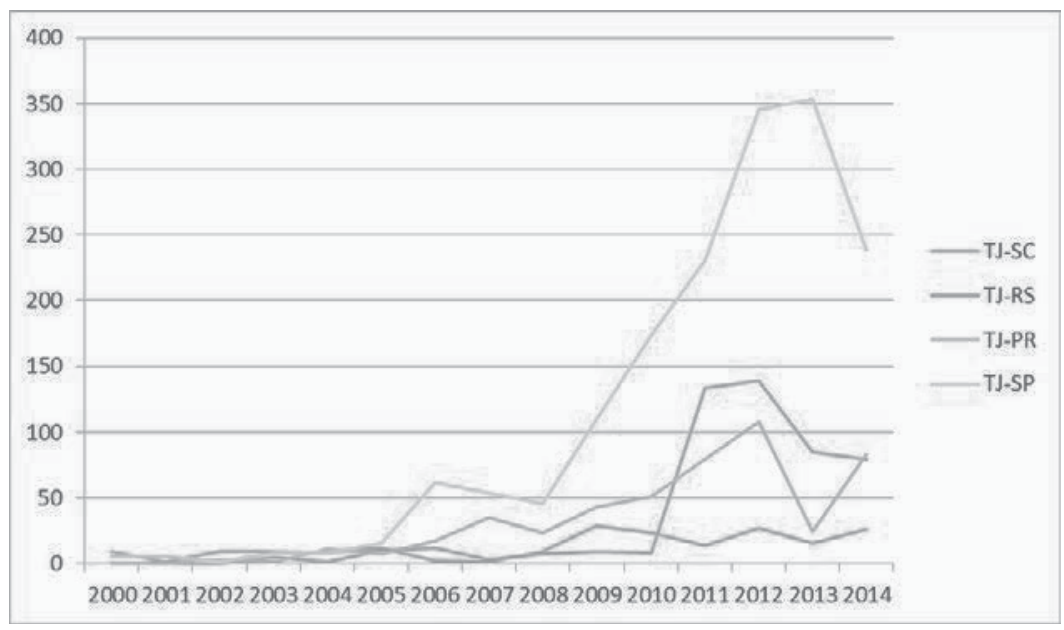

Fonte: Tribunal de Justiça do Rio Grande do Sul; Tribunal de Justiça do Paraná; Tribunal de Justiça de Santa Catarina; Tribunal de Justiça de São Paulo 
Os tribunais, em especial o de São Paulo, demonstram uma clara tendência crescente nas ocorrências, em especial no período entre os anos de 2008-2013.

Passa-se então a um diagnóstico mais detido sobre algumas dessas inúmeras decisões. Com vistas justamente a um maior aprofundamento em detrimento da abrangência, como já reiterado, opta-se pela dedicação exclusiva ao Tribunal de Justiça de Santa Catarina. O foco, também por uma necessidade de se restringir o escopo da análise, se dará principalmente nas decisões que possuem o termo punitive damages (demonstrado supra como o mais popular) em suas ementas.

Cumpre esclarecer que o juízo de valor utilizado na crítica de cada uma dessas decisões consubstancia-se em sopesar os argumentos dos magistrados com os parâmetros tradicionais do instituto, já sucintamente estabelecidos no primeiro momento desse estudo. Comentários positivos denotam um entendimento e/ou aplicação adequados; o inverso sendo também válido. Assim sendo, não se emitirá, por exemplo, juízo de valor quanto à, ainda, corrente discussão sobre a incompatibilidade do instituto com o nosso direito.

\subsection{Tribunal de Justiça de Santa Catarina (TJ-SC)}

São 14 os acórdãos que contemplam a expressão "punitive damages" em suas ementas no Tribunal de Santa Catarina.

As quatro primeiras delas tratam de apelações cíveis proferidas por um mesmo relator. As duas mais antigas enfrentam um caso de cobrança indevida de IPTU já pago, em que os particulares ajuizaram uma ação de danos morais contra seus respectivos municípios e ganharam a causa no primeiro grau. Os municípios então apelaram e o referido desembargador manteve a sentença de primeiro grau. $\mathrm{O}$ terceiro caso diz respeito a um acidente de trânsito envolvendo ônibus do município de Xanxerê, que levou a parte lesada a ajuizar uma ação buscando a indenização pelos danos sofridos (dentre eles, morais e estéticos). Novamente negou-se provimento à apelação do município. O último também envolve cobrança indevida, dessa vez de um débito fiscal, por parte do município de Araranguá. 
O resultado foi o mesmo das outras ações, entendendo-se que a indenização por dano moral era cabível.

Já de início se percebe que, fatidicamente, não se atenderam aos requisitos de conduta dolosa ou gravemente negligente, necessários a uma aplicação condizente do instituto. Em todos os casos, quais sejam: AC n. 2000.019426-3 (TJSC, 2001), AC n. 2002.007879-0-SC (TJSC, 2002), AC n. 2002.020062-5-SC (TJSC, 2003) e AC n. 2004.006224-9SC (TJSC, 2005), a ementa aparece com uma mesma redação, transcrita a seguir:

\section{INDENIZAÇÃO - DANO MORAL - CRITÉRIOS DE FIXAÇÃO DA VERBA - DIREITO COMPARADO.}

Para aferição dos fatores determinantes do prejuízo moral, deve o juiz, em se valendo da experiência e do bom senso (art. 335, CPC), aplicar o princípio arbitrium boni viri, exteriorizado pela doutrina e pela jurisprudência, nas circunstâncias do caso concreto (case law), na gravidade do dano, nas condições do lesante e do lesado (punitive damages, como no direito da Comonn [sic] Law) e nas demais causas eficientes na produção da ofensa, sendo a indenização proporcional ao agravo sofrido (art. $5^{\circ}, \mathrm{V}, \mathrm{CRFB}$ ) e apta a servir de elemento de coerção destinado a frear o ânimo do agressor, impedindo, desta forma, a recidiva.

(Grifo nosso)

Percebe-se confusão conceitual entre o caráter punitivo-pedagógico do dano moral e o instituto da indenização punitiva. Mesmo que se argumentasse que a menção ao instituto tenha sido feita no intuito de uma analogia entre a função punitivo-pedagógica do dano moral e a indenização punitiva, o paralelo não seria de todo válido, vez que na avaliação de um valor cabível à indenização punitiva não se leva em consideração a condição econômica do lesado, somente a do lesante (OWEN, 1988, p. 731).

Sobre o porquê disso, esclarece Andrade (2009, p. 303):

Já a situação socioeconômica da vítima não deve ser considerada na fixação do montante da indenização punitiva [...] porque não contribui para o alcance dos efeitos punitivo e preventivo da in- 
Punitive Damages: características do instituto nos Estados Unidos da América e transplante do modelo estrangeiro pela jurisprudência brasileira do Tribunal de Justiça de Santa Catarina

denização. Ao contrário, do ponto de vista estritamente racional, a consideração acerca da situação econômica da vítima culmina por reduzir a eficácia punitiva/preventiva da sanção em relação às vítimas de menor poder econômico, que, em comparação com as de maior poder econômico, ficam mais sujeitas a ataques a seus interesses não patrimoniais ${ }^{26}$.

Já em 2008, encontra-se o agravo de n. 2007.033273-3 (TJSC, 2008a), originário do município de Sombrio, com a seguinte ementa:

PROCESSUAL. REGIMENTO INTERNO. SANÇÃO CIVIL (PUNITIVE DAMAGE) APLICADA DE OFÍCIO EM SENTENÇA RESOLUTÓRIA DE LIDE INSTAURADA ENTRE CONSUMIDOR INDIVIDUALMENTE CONSIDERADO E INSTITUIÇÃO BANCÁRIA. TRANSAÇÃO CELEBRADA ENTRE AS PARTES. SENTENÇA HOMOLOGATÓRIA TRÂNSITA EM JULGADO COM A RESSALVA DA MULTA ADMINISTRATIVA. CUMPRIMENTO DA SENTENÇA LEVADA A EFEITO PELO MINISTÉRIO PÚBLICO. IMPUGNAÇÃO RECHAÇADA NA ORIGEM. AGRAVO DE INSTRUMENTO. COMPETÊNCIA RECURSAL. MULTA CIVIL DESTINADA A FUNDO INSTITUIIDO PARA A DEFESA DO CONSUMIDOR. ACTIO IUDICATI DEFLAGRADA COM A FINALIDADE DE DAR CONCREÇÃO A DIREITO TRANSINDIVIDUAL. DEMANDA EXECUTIVA DESVINCULADA DA LIDE ORIGINÁRIA. MATÉRIA AFEITA A UMA DAS CÂMARAS DE DIREITO PÚBLICO. ART. $3^{\circ}$ DO ATO REGIMENTAL N. 41/00. REDISTRIBUIÇÃO. (Grifo do original)

O caso trata de uma aplicação de ofício por parte do juiz de primeiro grau de uma multa (embasada nos artigos 56 e 57 do CDC) na soma de $\mathrm{R} \$ 40.000,00$, a ser depositada em conta judicial para reversão ao fundo municipal de defesa do consumidor, em caso envolvendo inscrição indevida em órgão de proteção de crédito pelo banco réu. Ocorre que após a

\footnotetext{
${ }^{26}$ Destaca-se, porém, que as condições pessoais da vítima, que pudessem influenciar na determinação de, por exemplo, a gravidade do dolo (no caso de termos uma vítima com algum retardo mental de quem o lesante tirou proveito); essas sim poderiam ser levadas em consideração, mas apenas para tal fim (ANDRADE, 2009, p. 304-305).
} 
decisão de primeiro grau as partes acabaram fazendo um acordo extrajudicial sobre a indenização por danos morais devidas pelo banco ao autor, sem mencionar a questão da multa. Porém, o Ministério Público propôs execução pelo valor da multa, a despeito dessa matéria não ter sido contemplada no acordo, que fez coisa julgada. O banco réu interpôs uma impugnação ao cumprimento de sentença, que foi rejeitada. Agravou ao Tribunal da decisão que rejeitou sua impugnação. Em sede de agravo, a desembargadora declina competência da Câmara de Direito Civil para a Câmara de Direito Público, vez que a matéria discutida não mais dizia respeito à relação entre os particulares, e sim exclusivamente à multa. $\mathrm{Na}$ resolução do caso, a Câmara de Direito Público considera o recurso da parte inadequado, concluindo que o banco deveria ter apelado. Como a matéria da sentença original transita em julgado, os valores são executados pelo Ministério Público e depositados no fundo municipal. Para além do imbróglio processual do caso, cumpre notar que a menção da desembargadora no agravo ao instituto da indenização punitiva é despropositada, já que o caso diz respeito à multa especificamente prevista em nossa legislação.

As quatro menções seguintes à expressão "punitive damages" feitas pelo Tribunal são de mesma relatoria, entre 2008 e 2009. Tratam de quatro apelações cíveis que, a despeito de suas peculiaridades específicas, irrelevantes para a apreciação em tela, abordam também casos de indenização por dano moral em que esta foi concedida. Como no exemplo anterior, a argumentação encontrada no acórdão é exatamente a mesma em todos. São estes: AC n. 2007.034951-8 (TJSC, 2008b), AC n. 2005.022932-0 (TJSC, 2009c), AC n. 2008.002463-3 (TJSC, 2009d) e AC n. 2007.007617-2 (TJSC, 2009e), e transcreve-se excerto relevante tirado das ementas:

$\mathrm{Na}$ fixação do quantum indenizatório, o magistrado deve sopesar a situação financeira das partes, o abalo experimentado pela vítima, a duração do dano, a fim de proporcionar uma compensação econômica para esta, sempre em atenção ao caráter pedagógico-punitivo da medida (teoria do punitive-damages), impedindo a prática de tais ilícitos. 
Por outra vez, percebe-se que o Tribunal incorre no equívoco de equivaler o instituto estadunidense ao caráter punitivo-pedagógico do nosso dano moral.

Os cinco últimos casos identificados com menção à expressão " $p u$ nitive damages" em ementa datam do ano de 2014 e são acórdãos em que a relatora chama o instituto à baila em sede exemplificativa, e com correta lição, em igual teor nas cinco decisões. Veja-se:

Por outro lado, avulta, hodiernamente, na linha do direito norte-americano (exemplary ou punitive damages), seu caráter punitivo, ou retributivo, de modo a sancionar o ofensor, sem prejuízo, como consectário deste viés, da prevenção geral (em face da comunidade) e especial (em face do autor), para que semelhantes condutas antijurídicas não sejam endossadas ou reiteradas - chamada também de disciplinar ou pedagógica (TJSC, 2014a; TJSC, 2014b; TJSC, 2014c; TJSC, 2014d; TJSC, 2014e).

No que diz respeito a outros casos do estado, cumpre mencionar que de todos os 204, o recorde de menções à expressão no corpo de suas decisões é de um mesmo desembargador, com 39. Em sua decisão mais recente, julgada em 2010, no caso AC n. 2009.035153-3 (TJSC, 2010), observou-se o seguinte:

c) "a justificativa da natureza punitiva da condenação por dano moral, não deve ser aceita, isto porque a Teoria do Desestímulo, espelhada no punitive damages do Direito Norte-Americano, tem recebido duras críticas da doutrina pátria, na tentativa de afastar indevidas investidas de enriquecimento ilícito";

No ano anterior, nos casos AC n. 2008.072470-2 (TJSC, 2009a) e AC n. 2009.030948-6-SC (TJSC, 2009b), ele houvera feito outra colocação (esta se repete nos dois casos), a saber:

Manifestação da lavra do Bel. Sérgio Pinheiro Marçal, advogado de São Paulo e feito publicar na R.T.D. (Revista do 3. ${ }^{\circ}$ Registro de Títulos e Documentos de São Paulo - Registrador José Maria 
Sivieiro), ao analisar a 'Teoria do Valor do Desestímulo' afirma que a falta de previsão legal tem permitido a incorreta aplicação do instituto do dano moral, gerando distorções. Alude à mesma doutrina, adotada no sistema jurídico americano com o nome de punitive damages, porquanto está se tornando 'um verdadeiro fator de desagregação da sociedade americana, onde os cidadãos tendem cada vez mais a afastar sua própria responsabilidade para imputá-la a terceiros. Cada vez menos as pessoas assumem os próprios erros ou opções, preferindo transferir a responsabilidade de seus atos a terceiros e obter algum dinheiro com isso' (n. 126, setembro de 1997).

A despeito do mérito da crítica do segundo excerto, e a exemplo dos julgados mais recentes analisados há pouco, o paralelo e a analogia aqui são corretos: o desembargador restringe-se a afirmar que a teoria do desestímulo é espelhada na teoria dos punitive damages, não que ambas se equivalham. Na contramão das decisões anteriores do mesmo sodalício, o desembargador, porém, é perceptivelmente contrário à utilização da função punitiva do dano moral, não a aplicando em suas decisões na determinação de um quantum indenizatório.

Dos 17 acórdãos catarinenses analisados (os 14 encontrados com menção à expressão "punitive damages" em suas ementas e três do desembargador mais prolífico sobre o assunto), pode-se concluir que nove acabam incorrendo em algum tipo de confusão conceitual, enquanto oito trazem abordagens cientificamente consistentes, aproximadas de um método funcional de direito comparado (SCHMIDT, 2011, p. 738-739).

\section{Conclusão}

Se, mesmo no exterior, onde após pelo menos um século desde seu surgimento, ainda subsistem debates quanto a sua eficácia, difusão, constitucionalidade, ou até quanto a melhor forma procedimental de aplicação e seus ditames básicos; não é de se surpreender que uma possível inclusão, ou a mera utilização, do instituto da indenização punitiva no nosso sistema jurídico seja suficiente para levantar uma série de problemas. 
Mesmo sabendo-se das divergências que os punitive damages geram nos Estados Unidos da América, país cujo ordenamento foi escolhido para respaldar o presente estudo, tentou-se traçar algumas características básicas do instituto, analisando-se, inclusive, as principais funções que ele desempenha no ordenamento alienígena.

O delineamento, ainda que não exaustivo, de um conceito operacional para a indenização punitiva mostrou-se importante para a verificação de sua (in)correta aplicação pela jurisprudência dos sodalícios selecionados. A aludida tarefa deu-se com alguma dose de audácia, já que as fronteiras conceituais entre a indenização punitiva e o caráter pedagógico do dano moral (largamente utilizado por grande parte da jurisprudência brasileira) não são um exemplo de precisão.

Com efeito, há pontos de sobreposição funcional entre os institutos citados, pois são, ambos, manifestações da controvertida função punitiva no âmbito da responsabilidade civil. Apesar dos percalços, empreendeu-se a análise de decisões judiciais, no intuito de verificar a correta aplicação da indenização punitiva na jurisprudência dos tribunais selecionados.

A pesquisa apresentou algumas conclusões alvissareiras, pois há muitos acórdãos que enfrentam a questão de maneira precisa, mesmo que muitos julgados ainda possam ser considerados exemplos de importação incorreta de modelos jurídicos estrangeiros.

Apesar do presente trabalho não se manifestar sobre a possibilidade de recepção do instituto no direito brasileiro, sublinha-se que a correta compreensão do conceito operacional da indenização punitiva é fundamental para um debate racional sobre a possibilidade de utilização da indenização punitiva em nosso ordenamento, tanto em relação ao atual estágio da nossa legislação, como somente de lege ferenda.

\section{Referências}

ANDRADE, André Gustavo de. Dano Moral \& Indenização Punitiva. 2. ed. Rio de Janeiro: Lumen Juris, 2009. 
AUSNESS, Richard C. Retribution and deterrence: the role of punitive damages in products liability litigation. Kentucky Law Journal, Lexington, v. 74, p. 1-125, 1985-86.

BELLI S. R.; MELVIN, M. Punitive Damages: their history, their use and their Worth in present-day society. University of Missouri-Kansas City Law Review, Kansas City, v. 49, n. 1, p. 1-23, 1980.

BITTAR, Carlos Alberto. Reparação civil por danos morais. 3. ed. São Paulo: RT, 1999.

CADY, Troy L. Disadvantaging the disadvantaged: the discriminatory effects of punitive damage caps. Hofstra Law Review, Hempstead, v. 25, n. 3, p. 1.005-1.039, 1997.

CALABRESI, Guido. The costs of accidents: a legal and economic analysis. New Haven: Yale University Press, 1970.

DANIELS, Stephen; MARTIN, Joanne. Myth and reality in punitive damages. Minnesota Law Review, Minneapolis, v. 75, p. 1-64, 1991.

DEAKIN, Simon; MARKESINIS, Basil. Markesinis \& Deakin's Tort Law. Oxford: Oxford University Press, 2008.

DOBBS, Dan B. Ending punishment in "punitive" damages: deterrencemeasured remedies. Alabama Law Review, Tuscaloosa, v. 40, n. 3, p. 831-917, 1989.

EISENBERG, Theodore; MILLER, Geoffrey P. The English versus the American rule on attorney fees: an empirical study of public company contracts. Cornell Law Review, Ithaca, v. 98, n. 2, p. 327-382, 2013. GARNER, Bryan A. Black's Law Dictionary. 9. ed. St. Paul, Minnesota: West Group, 2009.

GOTANDA, John. Punitive damages: a comparative analysis. Columbia Journal of Transnational Law, New York, v. 42, n. 2, p. 391-444, 2004. KEETON, William Page (Ed.). Prosser and Keeton on the Law of Torts. 5. ed. St. Paul: West Group, 1984. 
KOZIOL, Helmut; WILCOX, Vanessa (Ed.). Punitive damages: Common Law and Civil Law perspectives. Mörlenbach: SpringerWienNewYork, 2009. (Tort and Insurance Law, 25).

LANNI, Sabrina. La reelaboración de la responsabilidad civil: nuevos Códigos Civiles y diálogo Euro-Latinoamericano. Revista de Direito Civil Contemporâneo, São Paulo, v. 2, n. 4, p. 301-322, 2015.

LONG, John D. Punitive damages: an unsettled doctrine. Drake Law Review, Des Moines, v. 25, p. 870-892, 1976.

MARTINS-COSTA, Judith; PARGENDLER, Mariana Souza. Usos e abusos da função punitiva. Revista CEJ, Brasília, n. 28, p. 15-32, março de 2005.

MINER, Michael L. The expanding availability of punitive damages in contract actions. Indiana Law Review, Indianapolis, v. 8, p. 668-689, 1975.

MORAES, Maria Celina Bodin de. Danos à pessoa humana. Rio de Janeiro: Renovar, 2003.

. Punitive damages em sistemas civilistas: problemas e perspectivas. Revista trimestral de direito civil: RTDC, v. 5, n. 18, p. 45-78, abr.-jun. 2004.

NORONHA, Fernando. Direito das obrigações. 4. ed. São Paulo: Saraiva, 2013.

OWEN, David G. A punitive damages overview: functions, problems and reform. Villanova Law Review, Radnor Township, v. 39, p. 363-413, 1994.

. Punitive damages in products liability litigation. Michigan Law Review, Ann Arbor, v. 74, n. 7, p. 1.257-1.371, jun. 1976.

. The moral foundations of punitive damages. Alabama Law

Review, Tuscaloosa, v. 40, p. 705-739, 1988.

PIRES, Fernanda Ivo. Responsabilidade civil e o caráter punitivo da reparação. Curitiba: Juruá, 2014. 
ROSENVALD, Nelson. As funções da responsabilidade civil: a reparação e a pena civil. São Paulo: Atlas, 2013.

RUSTAD, Michael; KOENIG, Thomas. The historical continuity of punitive damages awards: reforming the tort reformers. American University Law Review, Washington, v. 42, n. 4, p. 1.269-1.333, 1993.

SANSEVERINO, Paulo de Tarso. Princípio da reparação integral. São Paulo: Saraiva, 2010.

SASSAMAN, Randy L. Punitive damages in contract actions - are the exceptions swallowing the rules? Washburn Law Journal, Topeka, v. 20, n. 1, p. 86-105, 1980.

SCHMIDT, Jan Peter. Responsabilidade civil no direito alemão e método funcional no direito comparado. In: RODRIGUES JUNIOR, Otavio Luiz; MAMEDE, Gladston; ROCHA, Maria Vital da (Coord.). Responsabilidade civil contemporânea: em homenagem a Sílvio de Salvo Venosa. São Paulo: Atlas, 2011. Cap. 46. p. 731-739.

SEBOK, Anthony J. Punitive damages in the United States. In: KOZIOL, Helmut; WILCOX, Vanessa (Ed.). Punitive damages: Common Law and Civil Law perspectives. Mörlenbach: SpringerWienNewYork, 2009. p. 155-196.

. Punitive damages: from myth to theory. Iowa Law Review, Iowa City, v. 92, p. 957-1036, 2007.

SILVA, Rafael Peteffi da; RODRIGUES JUNIOR, Otavio Luiz. Dano reflexo ou por ricochete: ponto de partida para a diferenciação dos sistemas brasileiro e português de responsabilidade civil extracontratual. In: SILVA, Rafael Peteffi da; CELLA, José Renato Grazieiro (Org.). I Encontro de Internacionalização do CONPEDI-Barcelona-ES: direito mercantil, direito civil, direito do consumidor, novas tecnologias. Barcelona: Laborum, 2015. v. 1, p. 37-72.

SULLIVAN, Timothy J. Punitive damages in the law of contract: the reality and the illusion of legal change. Minnesota Law Review, Minneapolis, v. 61, n. 2, p. 207-252, 1977. 
VENTURI, Thaís Goveia Pascoaloto. Responsabilidade civil preventiva: a proteção contra a violação dos direitos e a tutela inibitória material. São Paulo: Malheiros, 2014.

YÁGUËZ, Ricardo de Ángel. Daños punitivos. Cizur Menor (Navarra): Thomson Reuters, 2012.

\section{Jurisprudência}

ESTADOS UNIDOS DA AMÉRICA. Suprema Corte. BMW of North America, Inc. v. Ira Gore, Jr., 1996. 517 U.S. 559. Disponível em: $<$ https://www.law.cornell.edu/supct/html/94-896.ZS.html $>$. Acesso em: 29 dez. 2015. [EUA, 1996b]

. Suprema Corte. Pacific Mutual Life Insurance Co. v. Haslip, 1991. 499 U.S. 1. Disponível em: <http://www.law.cornell.edu/supct/ html/89-1279.ZS.html>. Acesso em: 29 dez. 2015. [EUA, 1991]

. Suprema Corte. Philip Morris USA v. Williams, 2007. 549 U.S. 346; 556 U.S. 178. Disponível em: <https://www.law.cornell.edu/supct/ html/05-1256.ZS.html>. Acesso em: 28 dez. 2015. [EUA, 2007]

. Suprema Corte. State Farm Mutual Automobile Insurance Co. v. Campbell, 2003. 538 U.S.408. Disponível em: <https://www. law.cornell.edu/supct/html/01-1289.ZS.html>. Acesso em: 5 jan. 2016. [EUA, 2003]

INGLATERRA. Câmara dos Lordes. Rookes v. Barnard, 21 de janeiro de 1964. [1964] UKHL 1. Disponível em: < http://www.bailii.org/uk/ cases/UKHL/1964/1.html>. Acesso em: 24 dez. 2012.

. Court of Common Pleas. Huckle v. Money, 1763. Disponível em: <http://press-pubs.uchicago.edu/founders/documents/amendIVs3. html>. Acesso em: 23 dez. 2012.

. Court of Common Pleas. Wilkes v. Wood, 1763. Disponível em: <http://www.bailii.org/cgi-bin/markup.cgi?doc=/ew/cases/EWHC/ CP/1763/J95.html>. Acesso em: 23 dez. 2012.

SANTA CATARINA. Tribunal de Justiça. Apelação cível n. 2000.019426-3, da Primeira Câmara de Direito Público. Relator: Volnei 
Carlin. Florianópolis, 19 de abril de 2001. Disponível em: <http://goo.gl/ Q9slk>. Acesso em: 10 jan. 2013. [TJSC, 2001]

. Tribunal de Justiça. Apelação cível n. 2002.007879-0,

da Primeira Câmara de Direito Público. Relator: Volnei Carlin. Florianópolis, 22 de agosto de 2002. Disponível em: <http://goo.gl/ aM9I4>. Acesso em: 10 jan. 2013. [TJSC, 2002]

. Tribunal de Justiça. Apelação cível n. 2002.020062-5, da Primeira Câmara de Direito Público. Relator: Volnei Carlin. Florianópolis, 10 de abril de 2003. Disponível em: $<$ http://goo.gl/ubI6v $>$. Acesso em: 10 jan. 2013. [TJSC, 2003]

. Tribunal de Justiça. Apelação cível n. 2004.006224-9, da Primeira Câmara de Direito Público. Relator: Volnei Carlin. Florianópolis, 26 de abril de 2005. Disponível em: <http://goo.gl/ iOS7x>. Acesso em: 10 jan. 2013. [TJSC, 2005]

. Tribunal de Justiça. Agravo de instrumento n. 2007.0332733, da Terceira Câmara de Direito Civil. Relatora: Maria do Rocio Luz Santarrita. Florianópolis, 3 de junho de 2008. Disponível em: <http://goo. gl/x8SJH1>. Acesso em: 10 out. 2015. [TJSC, 2008a]

. Tribunal de Justiça. Apelação cível n. 2007.034951-8, da Segunda Câmara de Direito Comercial. Relator: Wilson Augusto do Nascimento. Florianópolis, 3 de novembro de 2008. Disponível em: $<$ http://goo.gl/C0EmS >. Acesso em: 10 jan. 2013. [TJSC, 2008b]

. Tribunal de Justiça. Apelação cível n. 2008.072470-2, da Primeira Câmara de Direito Público. Relator: Newton Trisotto. Florianópolis, 23 de abril de 2009. Disponível em: <http://goo.gl/JgrhY>. Acesso em: 10 jan. 2013. [TJSC, 2009a]

. Tribunal de Justiça. Apelação cível n. 2009.030948-6, da Primeira Câmara de Direito Público. Relator: Newton Trisotto. Florianópolis, 18 de agosto de 2009. Disponível em: <http:/goo.gl/ Km4W2>. Acesso em: 10 jan. 2013. [TJSC, 2009b]

. Tribunal de Justiça. Apelação cível n. 2005.022932-0, da Segunda Câmara de Direito Comercial. Relator: Wilson Augusto do 
Nascimento. Florianópolis, 24 de agosto de 2009. Disponível em: $<$ http:// goo.gl/1HvdB $>$. Acesso em: 10 jan. 2013. [TJSC, 2009c]

. Tribunal de Justiça. Apelação cível n. 2008.002463-3, da Terceira Câmara de Direito Público. Relator: Wilson Augusto do Nascimento. Florianópolis, 3 de novembro de 2009. Disponível em: $<$ http://goo.gl/2s6Bo>. Acesso em: 10 jan. 2013. [TJSC, 2009d]

. Tribunal de Justiça. Apelação cível n. 2007.007617-2, da Terceira Câmara de Direito Público. Relator: Wilson Augusto do Nascimento. Florianópolis, 10 de novembro de 2009. Disponível em: $<$ http://goo.gl/YSXDU>. Acesso em: 10 jan. 2013. [TJSC, 2009e]

. Tribunal de Justiça. Apelação cível n. 2009.035153-3, da Primeira Câmara de Direito Público. Relator: Newton Trisotto. Florianópolis, 6 de abril de 2010. Disponível em: $<$ http://goo.gl/jdtVi $>$. Acesso em: 10 jan. 2013. [TJSC, 2010]

. Tribunal de Justiça. Apelação cível n. 2011.050121-4, da Terceira Câmara de Direito Comercial. Relatora: Rosane Portella Wolff. Florianópolis, 27 de mar. de 2014. Disponível em: <http://goo.gl/ zWVt51>. Acesso em: 10 set. 2014. [TJSC, 2014a]

. Tribunal de Justiça. Apelação cível n. 2011.008444-0, da Terceira Câmara de Direito Comercial. Relatora: Rosane Portella Wolff. Florianópolis, 8 de maio de 2014. Disponível em: <http://goo.gl/ q9EFwy>. Acesso em: 10 set. 2014. [TJSC, 2014b]

. Tribunal de Justiça. Apelação cível n. 2009.043323-7, da Terceira Câmara de Direito Comercial. Relatora: Rosane Portella Wolff. Florianópolis, 18 de setembro de 2014. Disponível em: <http://goo.gl/ c7HSBq >. Acesso em: 10 out. 2015. [TJSC, 2014c]

. Tribunal de Justiça. Apelação cível n. 2010.056860-6, da Terceira Câmara de Direito Comercial. Relatora: Rosane Portella Wolff. Florianópolis, 23 de outubro de 2014. Disponível em: <http://goo.gl/ PVGxlt>. Acesso em: 10 out. 2015. [TJSC, 2014d]

. Tribunal de Justiça. Apelação cível n. 2012.045519-2, da Terceira Câmara de Direito Comercial. Relatora: Rosane Portella Wolff. 
Florianópolis, 13 de novembro de 2014. Disponível em: <http://goo.gl/ qMY04R>. Acesso em: 10 out. 2015. [TJSC, 2014e]

SUPERIOR TRIBUNAL DE JUSTIÇA. Consulta Jurisprudencial. [2013]. Disponível em: <http://www.stj.jus.br/SCON/>. Acesso em: 10 jan. 2013.

TRIBUNAL DE JUSTIÇA DO RIO GRANDE DO SUL. Consulta Jurisprudencial. [2013]. Disponível em: $<$ http://www.tjrs.jus.br/site/ jurisprudencia/>. Acesso em: 10 jan. 2013.

TRIBUNAL DE JUSTIÇA DO PARANÁ. Consulta Jurisprudencial. [2013]. Disponível em: <http://portal.tjpr.jus.br/jurisprudencia/>. Acesso em: 10 jan. 2013.

TRIBUNAL DE JUSTIÇA DE SANTA CATARINA. Consulta

Jurisprudencial. [2013]. Disponível em: $<$ http://app.tjsc.jus.br/ jurisprudencia/>. Acesso em: 10 jan. 2013.

TRIBUNAL DE JUSTIÇA DE SÃO PAULO. Consulta

Jurisprudencial. [2013]. Disponível em: $<$ http://esaj.tj.sp.gov.br/cjsg/ consultaCompleta.do>. Acesso em: 10 jan. 2013.

Rafael Peteffi da Silva é doutor em Direito pela Universidade de São Paulo, professor adjunto da Universidade Federal de Santa Catarina e pesquisador líder do grupo "Direito Civil na Contemporaneidade".

E-mail: rpeteffi@terra.com.br

Endereço profissional: Universidade Federal de Santa Catarina, Centro de Ciências Jurídicas, Campus Universitário, Trindade, Florianópolis, SC - 88040900.

Mark Pickersgill Walker é doutorando em Direito Civil na Universidade Federal do Rio Grande do Sul, mestre e graduado em Direito pela Universidade Federal de Santa Catarina. Pesquisa temáticas relativas à Responsabilidade Civil 
com enforque em Direito comparado e especificamente o instituto dos punitive damages.

E-mail: mark.walker@ufrgs.br

Endereço profissional: Universidade Federal do Rio Grande do Sul, Faculdade de Direito, Av. João Pessoa n. 80, Centro Histórico, Porto Alegre, RS - 900040-000. 